\title{
Supply Chain Management Analysis: A Simulation Approach of the Value Chain Operations Reference Model (VCOR)
}

\author{
Carlo Di Domenico', Yacine Ouzrout ${ }^{2}$, Matteo M. Savinno ${ }^{1}$ \\ and Abdelaziz Bouras ${ }^{2}$ \\ ${ }^{1}$ University of Sannio - Dept. of Engineering, Piazza Roma, 21 - 82100 \\ Benevento, Italy \\ \{matteo.savino, carlo.didomenico\}@unisannio.it \\ ${ }^{2}$ LIESP Laboratory - University of Lyon (Lyon 2) \\ 160 Bd de l'université \\ 69676 Bron Cedex, France \\ \{yacine.ouzrout, abdelaziz.bouras\}@univ-lyon2.fr
}

\begin{abstract}
The impact of globalization and worldwide competition has forced firms to modify their strategies toward a real time operation with respect to customer's requirements. This behavior, together with the possibilities of communication offered by the up to date Information and Communication Technologies, moves the top management toward the concept of extended enterprise in wich a collaborative link is established among supplier, commercial partners and customers. When the information flows involves each agent of the chain, from suppliers to the final distribution centres, the extended enterprise becomes a virtual firm, which can be defined as a set of stand-alone operational units that acts to reconfigure itself as a value chain in order to adapt to the business opportunities given by Market. The present work is intended to verify the effective quantitative advantages given by the introduction of the Value Chain concept into the supply chain management through a simulation approach. The paper, after a description of SCOR and VCOR methods, makes a comparison between the two methods by the implementation of a simulation approach which point out the main additional requirements that are added to the VCOR model for its implementation.
\end{abstract}

\section{Keywords}

Supply Chain Management, Simulation, SCOR and VCOR Modeling, 


\section{Introduction}

Supply chain Management is one of the focus areas for companies and researchers over the last two decades. It deals with cost effective way of managing materials, information and financial flows from point of origin to the point of consumption to satisfy customer requirements. For a long time each member of the supply chain was considered as isolated, while nowadays, with the new ICT tools, companies are strictly integrated and in a Supply Chain Dynamics, A positive aspect of this dynamic is the effective collaboration which may lead to higher performance. A negative aspect is the independent decision making, which may create various delays and aggravate the forecasting error. The present paper deals with supply chain modeling and simulation, with discrete event approach, of the two main methods: SCOR and VCOR. Our main research interest in this work is to clarify the critical factors for minimizing the negative effects of supply chain dynamics and to gain insight on how to effectively manage them.

\section{Supply Chain and Value Chain Management}

A Supply Chain can be defined as a system network that provides raw materials, transforms them into intermediate commodities and/or in finished goods and distributes them to the customers through a delivery system [1]. The aim is to produce and distribute the right quantities, to the right locations, at the right time, while reducing costs and maintaining a high level of service.

Supply chain management (SCM) is recognized as a contemporary concept that leads in achieving benefits of both operational and strategic nature. SCM is concerned with smoothness, economically driven operations and maximizing value for the end customer through quality delivery. The limitations are mainly due to the fact that SCM as a concept does not extend far enough to capture customer's (end user) future needs and how these get addressed [2].

Another important theory that can be defined as strategic in the context of SCM is the concept of Value Chain Management. The Value Chain was described and popularized by Michael Porter in his 1985 best-seller, Competitive Advantage: Creating and Sustaining Superior Performance. Porter defined the "Value" as the amount that buyers are willing to pay for what a firm provides, and he conceived the "Value Chain" as the combination of generic activities operating within a firm, activities that work together to provide value to customers.

The huge importance of focusing on the customer has forced the integration of the optimization techniques of the SCM, Customer Relationship Management (CRM) and Product Lifecycle Management (PLM) (figure 1):

- PLM is a strategic business approach that helps enterprises to achieve its business goals of reducing costs, improving quality and shortening time to market, contemporarily innovating its products, services, and business operations. A definition can be: "a strategic business approach that applies a consistent set of business solutions in support of the collaborative creation, management, dissemination, and use of product definition information across the extended enterprise from the product concept to the end of its life, integrating people, processes, business systems, and information." [3]. 
- The CRM is the creation, the development, the palimony and the optimization of long period relationships more profitable among consumers and firm. The success of CRM is based on the understanding of the consumers' needs and desires, and it fulfils setting such desires to the center of the business, integrating them with the firm's strategy, the people, the technology and the business process [4].

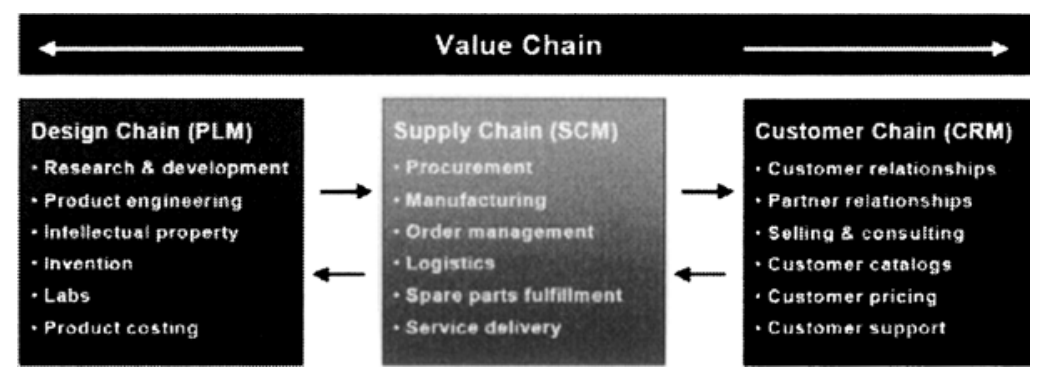

Fig. 1. Integration of PLM, SCM, and CRM from www.process-wizard.com

\section{SCOR vs VCOR modeling}

The VCOR model was developed from the perspective of being a value chain framework which supports and enables companies to integrate their three critical domains: Product Developments, Supply Network Integration and Customer Success, using one reference model to support the vision of an integrated Value Chain (VC). To achieve this goal VCOR uses a "process based common language". The main objective of this model is to increase the performance of the total chain and support the current evolution; for that, it proposes three main modeling layers:

- Strategic Level: The top level of the model includes all the high level processes in VCs and is represented through the Process Categories Plan-Govern-Execute.

- Tactical Level: The second level of the model contains "abstract" processes decomposed from the Strategic Level to implement and fulfill the strategic goals set in the top level of the model hierarchy.

- Operational Level: The third level of the model represents specific processes in the value chain related to actual activities being executed. In a VC perspective this is the level where fine-tuning occurs.

In order to measure the performance of the chain, the Supply Chain Council and the Value Chain Group (VCG) [8] have introduced different metrics and KPI to test supply chain reliability, responsiveness, flexibility, costs and efficiency in managing assets. According to the definition of the VCG a metric is "a quantifiable variable that reflects a specific state of business performance during process execution within a strategic value chain context". In VCOR a metric is characterized by different features: Metric Name, Definition, Priority, Metric Class \& Sub-Class, Formula, Input Requirements, Dimension, Calculation Rules, etc. We will use these metrics in the simulation model to analyze the dynamic and the performance of the processes. 


\section{The simulation of SCM and PLM processes}

Nowadays in literature there are few examples of simulated SC; moreover the number sensitively decreases if we consider the examples that apply the SCOR model [5][6][7]. This section presents first the advantages of simulation in comparison to the analytical and mathematical models and finally the realization of a generic architecture to simulate the VCOR model [8].

A SC is a dynamic, stochastic and complex system composed by a lot of actors; so in rare occasions it is possible to analytically model it. The benefits in using simulation in SCs can be summarized as follows [9][10]: Capacity to capture data for analysis; Decrease the risks inherent to changes in planning; Investigate the impact of innovations; Investigate relations between suppliers and other actors; Rationalize the number/size of order lots; Investigate opportunities to decrease the varieties of product components and standardize them throughout the SC...

\subsection{Problem Description}

The aim of this section is to illustrate the steps of our work, starting from the SCOR model simulation to the VCOR's one. We started from the level 1 of SCOR following a top-down approach. Once defined the Macro-Processes involved in each element of the chain, we choose their configuration and we depict the level 3 elements implicated in the work. To describe this model we use the following example of SC (figure 2).
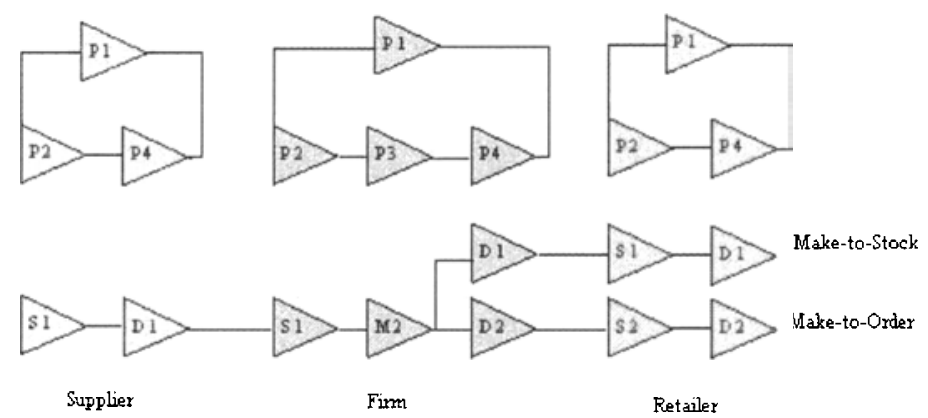

Fig. 2. Supply Chain Configuration

The Firm has a production process that transforms raw materials in finished goods using a Make process in its configuration. The other members, like Retailer and Suppliers, have only package processes that are included in the Deliver process. For some products, the production follows the rule of the Make-to-Stock, while for the others a Make-to-Order production is assigned. The simulation tool is based on the orders management; when any member needs a quantity of products it becomes a client and sends an order signal to its providers. An order is characterized by its identifier, quantity/type of product, timestamps and status (ordered, delivered...).

In this context, the necessary SCOR Level 3 elements have been realized in ARENA blocks and then gathered and organized in ARENA sub-models in order to set up the SCOR processes (figure 3). 


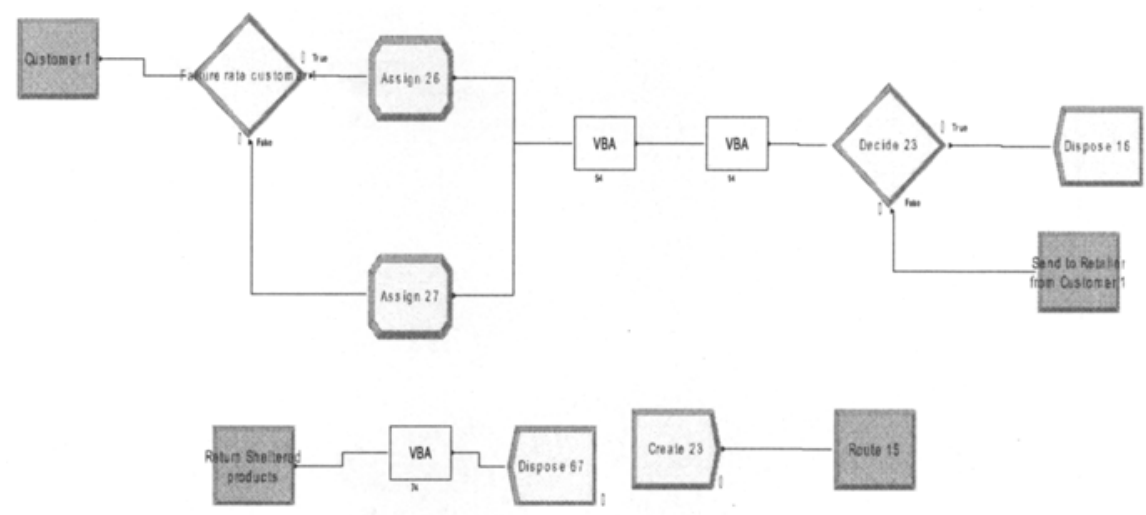

Fig. 3. Supply Chain Level 2: a sample of ARENA Implementation

\subsection{SCOR and VCOR Simulation}

We describe in this section the implementation of a sample actor of the chain: the retailer. It is composed by a Source and a Deliver process with two configurations: Make-to-Stock and Make-to-Order. An Arena block is implemented with a rule in which each request made by the consumer automatically becomes an order of the Retailer to the Firm. In the next figure the elements of the Source process are shown from the level 3 of SCOR. The Schedule Product Deliveries S2.1 has the role to check the inventory levels stored in the database. If the effective level is under an " $s$ " value, this module sends an order to the Firm, writing the order information's in the Firm's Demand database. The Receive Product $\$ 2.2$ receives the commodities send by the Firm and changes the order status to "Delivered". The Verify Product S2.3 element checks the incoming products and Transfer Product S2.4 transfers them in the inventory. The Retailer Inventory database is updated and the Customers demand can be satisfied. These generic processes based on SCOR are used for each actor of the SC (retailer, supplier, customer...) and implemented in the ARENA model.

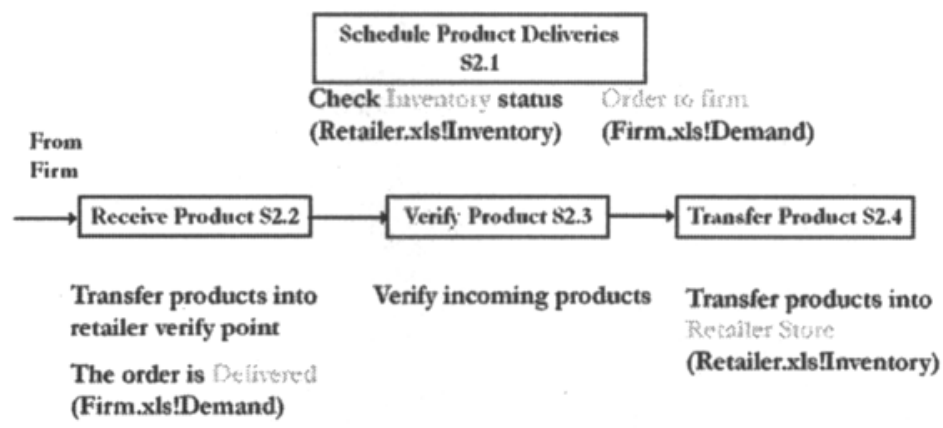

Fig. 4. Retailer SCOR Source process 
In a second phase, the specifics elements of VCOR processes: Market, Research, Develop, Sell and Support processes have been added in the ARENA model:

\section{a. Customer Behavior model}

The VCOR simulation needs a model for consumer behavior; we have adopted the Adaptive Learning Model [11] that consists in a mathematical model which is able to simulate the satisfaction level of the consumer. According to this model the customers express their level of satisfaction through a vote for each product. This vote decrements in an exponential way with the time (product's end of life), and increases if the support service, introduced in the VCOR model, is able to resolve the problems of the clients. It is possible thanks to an "Innovation Factor" in the mathematical model that is enabled when an old product is modified to meet the market's demands. Our consumer behavior model is adapted from the Hopkins's one and is formalized as:

$$
x_{i}(k+1)=(1-\alpha) \cdot x_{i}(k)+\alpha \cdot u_{i}(k)
$$

where:

$\mathrm{x}_{\mathrm{i}}(\mathrm{k})$ : the vote of the customer $\mathrm{i}$, at instant $\mathrm{k}$.

$\alpha$ : forgetting factor $(0<\alpha<1)$

$\mathrm{u}_{\mathrm{i}}(\mathrm{k})$ is the user input function

In our model $\mathrm{ui}(\mathrm{k})$ has the following expression

$$
u_{i}(k)=f(k) \cdot I_{n}+\xi \cdot s+\beta \cdot \Delta p+\delta \cdot d+\phi \cdot q+\eta \cdot x_{j \neq i}(k)
$$

where:

$\mathrm{s}$ : indicates if the last request of support was correctly satisfied (1) or not (-1)

$\xi$ : takes into account how important is the quality of service for the customer.

In our application's case a measurement system will be adopted with respect to the firm's customer satisfaction requirements.

\section{b. New Retailer configuration}

With the application of VCOR model, the Retailer configuration defines a new process. The Support element has the objective to solve the Customers problems when a delivered lot is defective (figure 5).

\begin{tabular}{|l|ll|}
\hline Manage Incident U/2 & Resolve Problem U3 & Monitor Experience U7 \\
\cline { 2 - 3 } $\begin{array}{l}\text { Register defective } \\
\text { order } \\
\text { (Retaile.xls!Support) }\end{array}$ & $\begin{array}{l}\text { Resolve Problem } \\
\text { (Retailer.xls!Demand) }\end{array}$ & $\begin{array}{l}\text { The resolved } \\
\text { problems have } \\
\text { good impact on } \\
\text { the client }\end{array}$
\end{tabular}

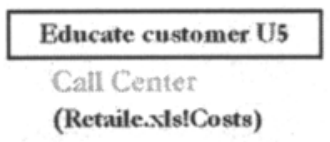

Fig. 5. Retailer VCOR Support process

The Manage Incident U2 has the role to register in the Support database the defective order, the quantity and type of products returned, the Customer identifier 
and the timestamps. The Resolve Problem U3 resolves the problem writing a new order in the Retailer Demand database with a quantity equal to the number of damaged products. Once that order is delivered the Monitor Experience $U 7$ registers the operation. It also modifies a variable in the Customer Behavior model that increments the vote. The Educate Customer U5 simulates a Call Center; it has the important goal to decrement the percentage of defective products caused by bad installation decrementing the value of a variable in a Customer ARENA module.

\section{c. Firm configuration}

The Firm has four new processes derived from PLM and CRM of the Value Chain Management. The Market, Research and Develop processes belong to PLM while the Sell process to the CRM. With these processes a company tries to analyze the market and take consequently strategic decisions, like the restyling of a product or the acquisition of new technologies. Since it is very difficult to reproduce a complex market analysis or a restyling of a product, the ARENA blocks simulate these events in terms of required time and associated costs. The Analyze Market MI module periodically checks the Customer satisfaction level in the Retailer Demand database and if the satisfaction goes down under a specified threshold activates the Architect Solution M4 module. This block finds the product type that has the least number of sales and decides to adapt it. In order to change a product, the Firm needs to modify its production line with the introduction of new technology. The Introduce Technology changes the production process in the VCOR Build Product B3 (figure 6)

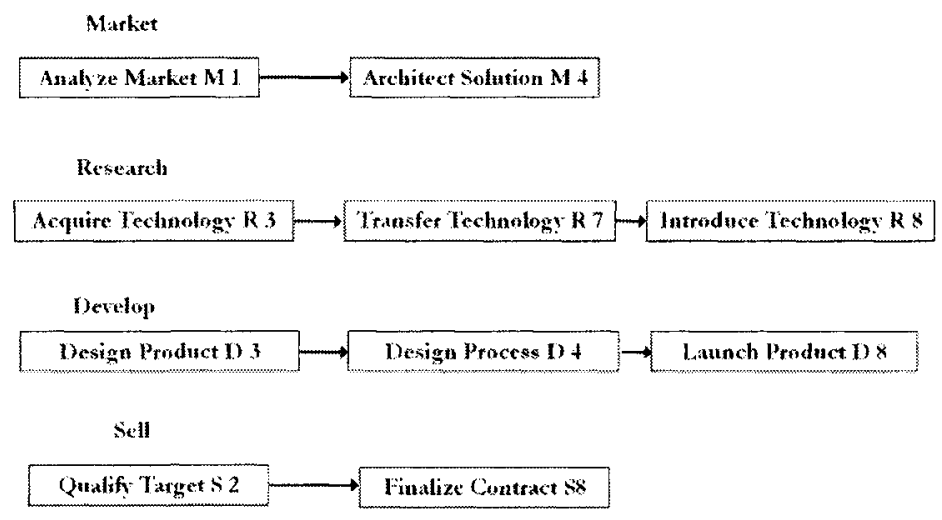

Fig. 6. Firm Market, Research and Develop processes

The Develop process materially changes the Bill Of Material of the product and it is responsible to launch the product. The D8, in fact, sets the variable "Innovation Factor" in the Customer Behavior model and, as consequence, the consumer vote considerably increases. The Sell process tries to identify the clients in the market in order to develop relationships and proposals. The Qualify Target $S 2$ classifies the Clients by the basis of their priority and determines which of them can be supplied by the Firm. It calculates, in fact, the total number of products required by the Clients and finalizes the contracts (S8) that don't exceed the fixed percentage of the dedicated production capacity. 


\section{Conclusion}

This paper has discussed the study of the two most famous models used to implement the concepts of Supply Chain Management and Value Chain Management: SCOR and VCOR, through a simulation approach. Starting from an analysis of their standard architectures, using a top-down approach, a simulation tool has been developed under the ARENA software. Once implemented the SCOR model on an example of supply chain, the tool was extended to VCOR.

As confirmed by some experimental results made to validate the simulator, the adoption of VCOR model is a huge financial and organizational stress, but these efforts are fully repaid by the benefits in term of quality of service, market extension, competitiveness, flexibility, "quick response", innovation and other features essential to survive in the Global Market. A future work could complete the implementation of templates about all the processes of VCOR model, extending the flexibility of the tool realized, with a validation test on a real industrial case study to obtain a robust simulation tool.

\section{Bibliography}

[1] M. Christopher, "Logistics And Supply Chain Management: Creating ValueAdding Networks" Ed. Prentice Hall; ISBN-13: 978-0273681762; (2004)

[2] A.S. Al-Mudimigh, M. Zairi, A.M. Ahmed. "Extending the concept of supply chain: The effective management of value chains" IJPE; Ed. Elsevier Vol.3; (2004)

[3] CIMdata: Product Lifecycle Management www.CIMdata.com

[4] Wen-Bao Lin "The exploration of customer satisfaction model from a comprehensive perspective" Expert Systems Application Vol. 33(1) (2007)

[5] Hermann, Lin and Pundoor "Supply Chain Simulation modeling using the Supply Chain Operations Reference Model". Inderscience Publicher; IJSCM Vol. 2 (2003)

[6] P. Bolstorff R. Rosenbaum. "SC Excellence: A Handbook for dramatic: improvement using SCOR Model" Ed. AMACOM; ISBN: 978-0814407301; (2004)

[7] J. Geunes, P.M. Pardalos, and H.E. Romeijn. "SCM: Models, Applications and Research Directions ", Kluwer Academic Publishers, ISBN 1-4020-0487-7 (2002)

[8] Value Chain Group. "EMEA Webpage" www.value-chain.org

[9] Boucher, Kuhn and Janke. "Integrated Modeling and Simulation of InterOrganizational Business Processes". (2003)

[10] H. Akkerman, "Emergent Supply Networks: System Dynamics Simulation of Adaptive Supply Agents"Proceeding of the 34th Hawaii ICSS'01. (2001)

[11] Ed Hopkins "Adaptive Learning Models of Consumer Behavior" Levine's Bibliography - UCLA Department of Economics (2006) 